\title{
Breast Cancer in Sub-Saharan Africa: How Does It Relate to Breast Cancer in African-American Women?
}

\author{
Alero Fregene, M.D. \\ Lisa A. Newman, M.D., M.P.H.
}

Department of Surgery, University of Michigan Comprehensive Cancer Center, University of Michigan, Ann Arbor, Michigan.

\begin{abstract}
Address for reprints: Lisa A. Newman, M.D., M.P.H., University of Michigan, 1500 East Medical Center Drive, 3308 CGC, Ann Arbor, Ml 48109; Fax: 734647-9647; E-mail: lanewman@umich.edu
\end{abstract}

Received September 8, 2004; revision received November 2, 2004; accepted December 20, 2004.

\begin{abstract}
BACKGROUND. African-American women have had a lower incidence, yet higher mortality rate from breast cancer compared with White-American women. AfricanAmerican women also have had a higher risk for early-onset, high-grade, nodepositive, and hormone receptor-negative disease. Similar features have characterized hereditary breast cancer, prompting speculation that risk factors could be genetically transmitted. Further evaluation of this theory required the study of breast cancer among women from sub-Saharan Africa because of their shared ancestry with African-American women.
\end{abstract}

METHODS. Publications from 1988 to 2004 of English-language literature on breast cancer in Africa were reviewed.

RESULTS. Women from sub-Saharan Africa were found to have a low incidence of breast cancer. This was partly explained by a largely protective reproductive history, including late menarche, early menopause, high parity with prolonged breastfeeding, irregular menses, and fewer ovulatory cycles. The average age at diagnosis, however, was approximately 10 years younger than breast cancer patients of western nations, and disease stage distribution was shifted toward more advanced disease, which resulted in higher mortality rates. These features were found to be similar to data on breast cancer in African-American women. Mutations in BRCA1 and BRCA2 have been reported in African-American women, but the extent of the contribution of BRCA1 and BRCA2 to breast cancer burden in Africa was uncertain. Limited financial resources lead to suboptimal cancer data collection, as well as delayed diagnosis and treatment of many African breast cancer patients.

CONCLUSIONS. Parallels between breast cancer burdens of African-American and sub-Saharan-African women were provocative, indicating the need for further exploration of possible genetically transmitted features related to estrogen metabolism and/or breast cancer risk. Cancer 2005;103:1540-50.

(C) 2005 American Cancer Society.

KEYWORDS: breast cancer, African-American women, African women, hereditary breast cancer.

D ata from the Surveillance, Epidemiology, and End Results (SEER) Program on the breast cancer burden of American women have documented paradoxical rates of incidence and mortality for African Americans compared with White Americans over the past 30 years. ${ }^{1}$ Ethnic background for SEER population-based rates are generally based on self-reported information from case ascertainments of participating tumor registries combined with data from the United States of America (USA) Census Bureau. Despite the substantial heterogeneity of ethnic ancestry that exists within many African-American families, a disproportionate risk for breast cancer mortality has been consistently demonstrated for women who identify themselves 
FIGURE 1. Nations within the continent of Africa. Known sites of slave trade ports during the colonial years were located in the western African nations of Nigeria, Ghana, Cameroon, Togo, Benin, Burkina Faso, Ivory Coast, Gambia, Guinea, Senegal, Guinea Bissau, and as far south as Angola. The term sub-Saharan Africa includes these nations, as well as The Republic of the Congo, Zambia, Zimbabwe, Botswana, Namibia, Kenya, Uganda, and South Africa.

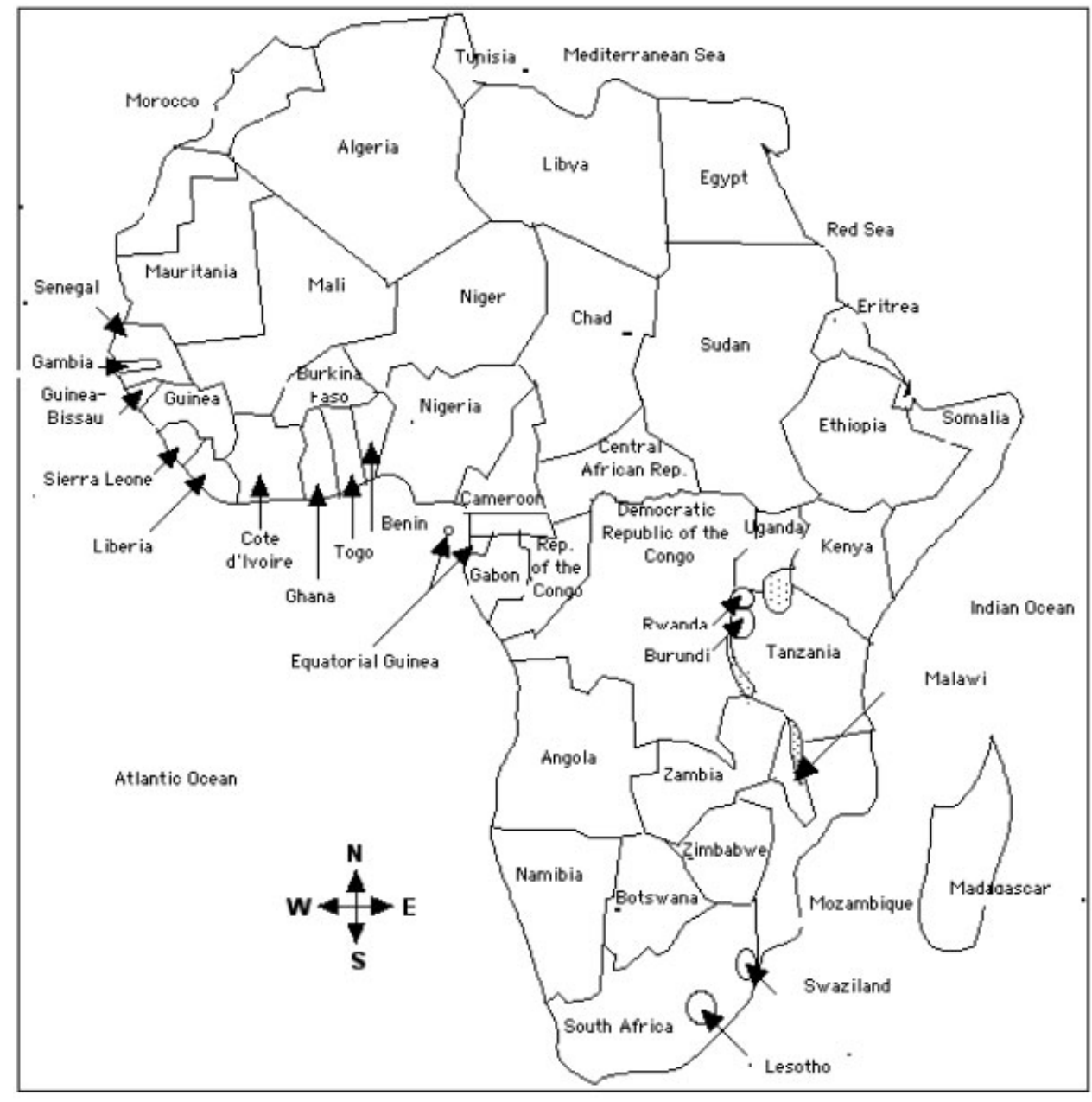

as African American. African-American women have a lower lifetime risk of being diagnosed with breast cancer, accounting for approximately $8 \%$ of all estimated new cases in the USA. In contrast, they account for approximately $13 \%$ of all breast cancer deaths. ${ }^{1}$ Further, African-American and White-American women have different age-incidence curves for breast cancer. Among women younger than 45 years of age, incidence is higher for African-American women. The median age of breast cancer diagnosis for African-American patients is 57 years, compared with 63 years for White-American women, and the corresponding median ages at death are 61 and 70 years, respectively. ${ }^{1}$

Studies of ethnicity-related variation in breast cancer burden within the USA have also demonstrated that African-American women are more likely to be diagnosed with estrogen receptor-negative, highgrade tumors that are node-positive..$^{2-8}$ These disease patterns also characterize the tumors that occur in women who harbor mutations in breast cancer susceptibility genes, prompting speculation that hereditary factors may explain some ethnicity-related issues.
Unfortunately, results from genetic counseling and testing programs in African-American women are limited. To learn more about breast cancer predisposition that may be related to inherited factors associated with African heritage, it is appropriate to study available data on the breast cancer burden of African populations that share ancestry with African Americans. Most of the colonial slave trade from the 1500s to the 1800s occurred between ports along the Atlantic coast and western, sub-Saharan Africa (frequently termed the "gold coast"). ${ }^{9}$ The goal of the current review article is, therefore, to analyze published data on breast cancer in populations from this region. Figure $1 \mathrm{dem}-$ onstrates the geography of various nations within the large continent of Africa.

\section{MATERIALS AND METHODS}

A review of medical literature on breast cancer in Africa published between 1988 and 2004 was conducted. Studies included here were limited to reports published in the English language. A Medline (Na- 
tional Library of Medicine, National Institutes of Health, Bethesda, MD) search with the keywords breast cancer and Africa yielded more than 300 titles, but review of their associated abstracts revealed that fewer than $25 \%$ of these contained appropriate data, defined by inclusion of information on incidence, mortality, epidemiology, and molecular biology of female breast cancer in sub-Saharan Africa. Case reports were excluded. Studies with fewer than 50 patients and those that focused on the Northern African countries of Morocco, Tunisia, Algeria, and Egypt were excluded.

Age-incidence curves for breast cancer are cited extensively in the reviewed studies, and the term early-onset is used frequently, with varying age cutpoint definitions. Application of the expression within this review article generally indicates breast cancer that occurred in the premenopausal $(<45$ yrs $)$ age range.

\section{RESULTS}

\section{Epidemiology}

\section{Breast cancer incidence and mortality rates in africa} compared with international rates

Epidemiologic studies reveal marked geographic variation in worldwide, observed breast cancer burden, shown from 1990-2002 case ascertainments. Age-adjusted breast cancer detection rates in North America, Northernern Europe, Australia, and New Zealand average 95-100 cases for 100,000 persons. In contrast, incidence is quite low in western Africa and eastern Asia, at approximately 20 per 100,000 . As shown by Figure 2, there is also substantial variation in breast cancer incidence and mortality rates among regions within the continent of Africa. ${ }^{10,11}$ Estimates of agestandardized incidence rates (per 100,000 women) are 20.2 in eastern Africa, 13.5 in middle Africa, 24.8 in western Africa, and 31.8 in southern Africa. ${ }^{11}$ Some of the variation in breast cancer impact that is observed among countries may be related to differences in their contemporary ethnic composition. Incidence curves reported from South Africa, for example, reflect a heavily mixed population of native African women as well as women of Anglo-European background. ${ }^{12}$ Comparisons between population subsets reveal progressively decreasing lifetime risk of breast cancer for white South Africans (1 in 13) versus mixed ethnicity South Africans (1 in 63) versus black South Africans (1 in 81$).{ }^{12,13}$

While the breast cancer incidence and mortality rates remain highest in fully industrialized nations, rates are rapidly increasing in developing countries. In Uganda, breast cancer incidence has doubled from 11 per 100,000 in 1961 to 22 per 100,000 in $1995 .{ }^{14}$ This increase has been attributed to the adoption of west-

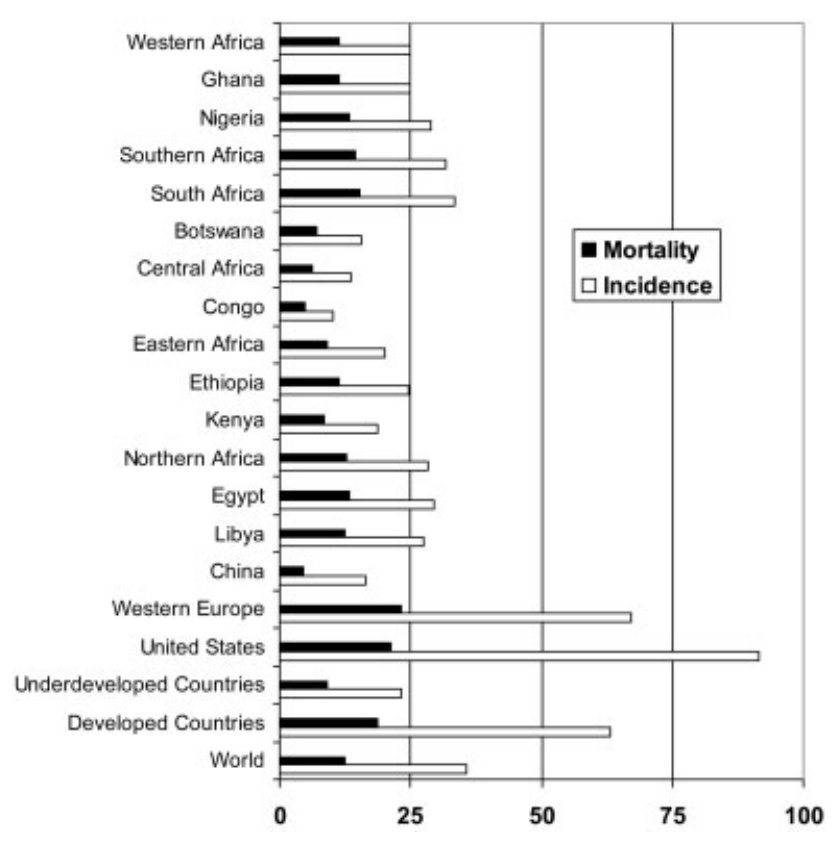

FIGURE 2. Breast cancer incidence and mortality among women of African nations compared with the USA and other international populations. ${ }^{11}$ Rates shown are per 100,000 persons.

ernized lifestyles; however, improvements in data collection and reporting may also be contributing factors.

Significant problems exist in obtaining accurate incidence rates in developing countries. Few have cancer registries that can provide incidence rates covering intervals 15 years or longer. Several of the most mature registries cover relatively small populations. Further, difficulty with estimating population denominators creates an additional barrier to the calculation of incidence and mortality rates. ${ }^{15}$ South Africa is one of the few nations that support population-based collection of cancer data, via their National Cancer Registry. However, because this registry relies on information submitted by pathology laboratories for case ascertainment, it is suspected that their statistics may underestimate actual cancer burden. ${ }^{13}$

Despite these data collection challenges, several aspects of breast cancer burden in African women have been well characterized and confirmed, such as their lower lifetime risk of developing the disease compared with Americans and women of Anglo-European ancestry. African breast cancer patients are also more likely to be premenopausal. ${ }^{16,17,18}$ Breast cancer incidence peaks between the ages of 35 and 45 years, approximately 10-15 years earlier than peak incidence for western countries outside of the western Africa region. ${ }^{16-23}$ A study from South Africa ${ }^{24}$ and one from Zimbabwe $^{19}$ reported a second, but smaller, increase in incidence occurring between the ages of 60 and 69 
years. Reports from other regions in Africa demonstrate a consistent decline in breast cancer risk following menopause, which is in sharp contrast to the rising incidence rates seen among postmenopausal women from North America and Europe.

It has been postulated that the lower postmenopausal breast cancer incidence rates observed for Africans are a consequence of demographics, especially population age and overall life expectancy. ${ }^{25} \mathrm{Com}-$ pared with expected longevity of American women (79 yrs), Ghanaian women have a life expectancy of 58 years; Nigerian, 51 years; Kenyan, 50 years; and South African women, 52 years. ${ }^{26}$ This unfortunate truncation of lifespan precludes the ability to make robust conclusions regarding risk of postmenopausal breast cancer. It has also been suggested that breast cancer case ascertainment is disproportionately low among older African women because of their lower literacy rates, poor socioeconomic status, and diminished awareness of breast cancer. ${ }^{16}$ It is also possible that breast cancer age-incidence curves in Africa reflect cumulative population-based risks attributable to lifestyles of preindustrialized societies, because premenopausal breast cancer incidence rates have been rising in westernized populations.

Breast cancer mortality rates are disproportionately high among African women compared with their generally low incidence rates. Although breast cancer incidence is 5-10 times higher in westernized populations, breast cancer mortality is only 2-3 times higher, and the mortality rate approaches equivalence in some parts of Africa. Estimated age-standardized mortality rate for women with breast cancer in 2000 was 15.6-21.4 in Africa compared with 27.7 in the USA and Canada. ${ }^{10}$ Within Africa, age-standardized mortality rates were estimated at 9.18 for eastern Africa, 6.18 for middle Africa, and 14.45 for southern Africa. ${ }^{11}$ The higher mortality risk among African breast cancer patients can be attributed to several different factors, including delayed presentation, limited therapeutic modalities, and, perhaps, a predisposition to biologically aggressive tumors.

There is a common misconception that noncommunicable diseases, such as cancers, are of inconsequential magnitude compared with communicable diseases in underdeveloped countries. ${ }^{10}$ Although the proportion of deaths from breast cancer is higher in developed countries, worldwide population densities and demographics are such that over $50 \%$ of all breast cancer deaths occur in underdeveloped countries; it is also estimated that by the year 2020, approximately $70 \%$ of new cancers cases will occur among individuals in developing countries, and a substantial fraction of these are likely to be breast malignancies. ${ }^{27,28}$

\section{Risk factors}

Gynecologic and reproductive factors. The gynecologic and reproductive patterns within African populations tend to result in fewer ovulatory cycles over a lifetime, and this contributes to a decrease in breast cancer risk. Although published studies have generally been small, the trends observed have included late menarche, multiparity, initiation of childbearing at young ages, and prolonged lactation. All of these features lead to lower endogenous estrogen levels over a lifetime, thereby diminishing cumulative breast cancer risk.

Several studies have reported that African women experience menarche at older ages (median, 15 years) compared with western women. ${ }^{17,19,29}$ Other studies have documented an increased parity history in African communities, averaging a reported 5-9 live births per woman. ${ }^{19,30,31}$ Menopausal history among African women has not been well documented. Of 14 patients surveyed in one study from Zimbabwe, the median age at menopause was 50 years. ${ }^{19}$

Childbearing begins at relatively younger ages among African women as well. ${ }^{29}$ One study reported a median age at first pregnancy of 19 years ${ }^{19}$ among 28 women surveyed. Rosenberg et al. ${ }^{2}$ evaluated breast cancer risk in relation to parity among South African women and found patterns similar to those observed in western populations. In the Rosenberg et al. study, women of mixed ethnic background with first childbirth at age 30 years or older had a twofold increase in breast cancer risk compared with women who had their first child at age 16 years or younger. ${ }^{29}$ In another study from South Africa, women who developed breast cancer had an older age at first birth and a higher level of education compared with control groups. ${ }^{32}$ In contrast, another study of nearly 2000 African breast cancer patients, reported by a Nigerian medical center, failed to identify any correlation between breast cancer risk and parity, risk and age at menarche, or risk and lactation. ${ }^{23}$

Extended postpartum lactation has also been reported among African women, and this reproductive pattern is likely to decrease lifetime incidence of breast cancer by decreasing the cumulative number of ovulatory menstrual cycles. In one study, $96 \%$ of patients breastfed for an average of 16 months. ${ }^{19}$ Coo$\operatorname{gan}^{32}$ et al. evaluated decreased breast cancer risk related to lactation among South African women and postulated that lactation causes differentiation of ductal epithelial cells, which is protective against carcinogens. ${ }^{32}$ Increased prolactin levels may also contribute to this process. In an interesting study on the Dogon of Mali (a traditional western African popula- 
tion), women were found to have a median of only 2 menses each over a 2-year study period. ${ }^{31}$ The median number of menses per lifetime was approximately 100 , representing $33 \%$ of the number experienced by an average American woman with a history of 3 live births. ${ }^{31}$

Diet. A typical diet in Africa consists mostly of grain, vegetables, and fiber with little fat and protein. This nutritional intake pattern may also be protective against breast cancer risk. ${ }^{33,}{ }^{34}$ Physiologically relevant concentrations of a potential chemopreventive agent (by means of dose-dependent inhibition of DNA synthesis) has been identified in at least one vegetable, Vernonia amygdalina, that is consumed heavily in western Africa. ${ }^{35}$

Body habitus. Body habitus has been implicated in breast cancer risk through complex pre- and postmenopausal factors. In postmenopausal women, the effect of obesity can be explained by increased extraglandular conversion of androstenedione to estrone by aromatase enzymes in the body's fat deposits. The effect of height and premenopausal body habitus on breast cancer risk is less well understood but is probably related to some indirect correlation with genetics, exercise levels, body mass, and menstrual irregularities. A case-control study from urban Nigeria, involving 234 breast cancer patients, suggested that postmenopausal obesity was associated with breast cancer risk when measured as a function of waist-hip ratios. ${ }^{36}$ Another analysis of the same population failed to demonstrate this association when obesity was estimated by body mass index to be $\geq 30$ but did report that increasing height was significantly correlated with breast cancer risk. ${ }^{21}$

Lifestyle, culture, and socioeconomic status. African nations are typically poorer than western, industrialized countries, and this is likely to be a factor in limiting available medical technology for cancer screening and treatment. Socioeconomic status is also associated with a variety of lifestyles and dietary practices that will affect breast cancer risk.

Studies of immigrant populations suggest that environment plays a significant role in modifying breast cancer risk associated with some ethnic backgrounds. Asian women, for example, typically face relatively low risk of breast cancer diagnosis. However, second- and third-generation female members of Asian families that immigrated to the USA develop breast cancer incidence rates that approach those of White American women. ${ }^{37}$ Presumably, this shift in breast cancer risk is related to adoption of westernized lifestyle and diet. Similar comparisons between generations of African Americans are not available, and the authors of the current review, therefore, have less data regarding the effect of environment versus African ancestry on breast cancer risk.

One study from South Africa has reported a doubling of breast cancer incidence rates in women living in urban areas compared with those residing in rural areas. ${ }^{12}$ Urban areas frequently are characterized by westernized behaviors and lifestyles. More affluent women typically reside in urban areas, and these differences in incidence rates, therefore, and at least partly, reflect differences in age of menarche, parity, and age at first live birth, and age at menopause.

Family history and benign fibrocystic proliferative changes. Little has been reported regarding benign fibrocystic disease and family history of breast cancer among Africans. Anyanwua ${ }^{17}$ compiled breast cancer data from 4 different hospitals in Nigeria and found a positive family history in $4 \%$ of cases; $12 \%$ of patients reported a prior history of benign fibrocystic breast changes.

\section{Disease Presentation}

Breast cancers in African countries are typically characterized by a relatively advanced stage distribution. One study reported a mean primary tumor diameter of $10 \mathrm{~cm}$ in 129 Nigerian women, and matted axillary lymph nodes were reported in more than half of these cases. ${ }^{18}$ Other retrospective studies have reported that $70-90 \%$ of African women present with Stage III or IV disease. ${ }^{16,18,19,38,39}$ Further, it can be reasonably conjectured that the clinical stage of many patients is underestimated because of the lack of proper diagnostic facilities.

The advanced stage distribution is at least partially explained by delayed presentation for medical evaluation, which has been reported to range from 2 weeks to 11 years ${ }^{17}$ following development of a selfdetected breast abnormality One study of 2033 black and white patients from South Africa demonstrated that these delays among black Africans resulted in significantly larger tumors and more advanced nodal pathology compared with white South Africans. ${ }^{40}$

The possibility of inherently more aggressive tumor biology among African women also exists. Findings from Hassan et al. ${ }^{18}$ support this theory. These investigators found that 17 of 21 patients $(81 \%)$ with a brief symptom duration (3 months or less) had Stage III or IV breast cancer. Ikpatt et al. ${ }^{41}$ conducted a detailed pathologic analysis of the proliferative activity in tumors of 300 Nigerian women and reported that 
mitotic indices were notably higher than the range of values typically reported from western databases.

The majority (approximately 85\%) of tumors among African women are invasive ductal lesions. ${ }^{16,38}$ This is similar to the histopathologic predominance observed in western populations. Bjerregaard et al. ${ }^{42}$ commented on the difficulty of evaluating prevalence of the more unusual types of breast cancer because of the frequency of detecting advanced-stage, poorly differentiated tumors that have lost any distinguishing features.

\section{Tumor Biology and Genetics}

Unfortunately, there is a paucity of studies on subSaharan Africa detailing biology or genetics of breast cancer. One formidable hindrance involves obtaining and processing tissue samples (usually because of financial considerations). There is also difficulty obtaining family history due to decreased awareness of breast cancer in sub-Saharan Africa and due to the desire for secrecy that is sometimes found within families following a diagnosis of cancer. ${ }^{17}$

Ikpatt et al. have published studies of several hundred patients defining the biology of breast tumors in African women. In these studies, comparisons of tumors from Finnish and Nigerian breast cancer patients showed that Nigerian breast tumors had more extensive necrosis, more nuclear atypia, and a higher proliferative activity. ${ }^{41,43,44}$

A diverse spectrum of BRCA1 and BRCA2 mutations and sequence variations unique to Africans has been reported. A screening of 206 black South African women with breast cancer revealed 3 common BRCA1 mutations: 185delAG in exon 2, 4184del4 in exon 11, and 5382insC in exon 2022. A second study of the coding regions of BRCA1 and BRCA2 genes from 70 Nigerian patients diagnosed with breast cancer before the age of 40 years revealed 2 novel BRCAl truncating mutations, Q1090X and 1742insG; four BRCA1 missense variations; one BRCA2 truncating mutation, 3034del4, previously unreported in anyone of African descent; and 20 nontruncating variants were detected in BRCA2. ${ }^{45}$ BRCA1 and BRCA2 mutations and sequence variations are potentially significant in cases of early-onset breast cancer within Africa. However, only a small portion of the mutations were protein truncating, fewer than those observed among white women. ${ }^{46}$

Overexpression of the protooncogene, Her-2/neu, is reported in approximately $15-30 \%$ of invasive breast cancers. Her-2/neu (c-erbB-2) overexpression has been associated with advanced tumor grade, size, and nodal status, and with shorter disease-free and overall survival, especially in patients with node-positive tu- mors; the role of HER-2/neu in patients with nodenegative breast cancer is more controversial, but overexpression of this oncogene has become increasingly important in the current era of targeted cancer therapy. ${ }^{47}$ A single nucleotide polymorphism of Her-2/neu at codon 655, GTC/valine to ATC/isoleucine (Val655Ile), which results in a guanine to adenine transition in the transmembrane domain coding region, has been identified. ${ }^{48}$ Women with a Val allele had an increased risk of breast cancer, especially younger women.

In a study that examined Her-2/neu polymorphism in African women, blood from 200 Ghanaian, 257 Caucasian, and 90 African-American healthy women was genotyped. ${ }^{49}$ The Val allele was not found in African specimens, but it was found in $20 \%$ of Caucasians and $24 \%$ of African-Americans. These results are consistent with genetic admixture between Africans and Caucasians residing in the USA. It also suggests that African women are unlikely to carry the Val polymorphism in Her-2/neu that is associated with increased risk for early-onset breast cancer.

\section{Ongoing Problems: Diminished Health Care Resources, Lack of Breast Cancer Awareness, and Competing Health Care Threats \\ Limited healthcare resources}

Developing countries have few resources allocated for healthcare. The World Health Organization reports that total health expenditure per capita is $\$ 31$ in Nigeria, \$60 in Ghana, \$114 in Kenya, and \$652 in South Africa, compared with $\$ 4887$ in the USA. ${ }^{50}$ The lack of financial resources in sub-Saharan Africa leads to fewer hospitals with limited staff, diagnostic equipment, and treatment facilities. For example, the country of Uganda has only two screening mammography units. ${ }^{14}$

Treatment of breast cancer in sub-Saharan Africa is largely limited to surgery because of advanced stage at presentation and limited access to diagnostic imaging as well as adjuvant therapy. Mastectomy is, therefore, the treatment of choice for the majority of cases. Another study cited the expense of traveling long distances to a hospital as a primary reason for patients having to restrict their therapeutic options. ${ }^{19}$

In an 11-year study of 374 women at the Kenyatta National Hospital, researcher Othieno-Abinya noted that systemic therapy and radiation were underused because of limited resources, with fewer than $10 \%$ of patients receiving adjuvant chemotherapy. ${ }^{51}$ In Cameroon, oophrectomy has been offered to women under 50 years of age because it is relatively inexpensive compared with a 5-year course of treatment with tamoxifen. ${ }^{52}$ In contrast, cost of testing frequently pre- 
cludes the ability to determine hormone receptor status, and some facilities resort to prescribing tamoxifen empirically. ${ }^{51}$

Radiotherapy is available only at larger urban hospitals. Despite World Health Organization recommendations for a minimum of 0.4 radiation therapy units per 1 million persons, many African countries have no radiotherapy facilities at all. ${ }^{27}$ In comparison, the USA has 12 machines per 1 million persons.

Lack of awareness. Even among the more affluent African women, breast cancer awareness tends to be relatively low on their list of health care priorities. A cross-sectional survey of 204 Nigerian nurses revealed that $31 \%$ of nurses were unfamiliar with breast cancer risk assessment, and most believed that they themselves were not at any risk. ${ }^{53}$

In another survey study conducted among 200 schoolteachers randomly selected from 12 schools in Lagos, Nigeria, ${ }^{54} 85 \%$ knew that breast cancer was a serious disease, but only $53 \%$ realized that a breast lump was a significant symptom. . Other warning signs were even less well known. Only $14 \%$ knew the methods used for diagnosis, and knowledge of risk factors was also poor. Although breast self-examination was practiced by $62 \%$ of respondents, only $11 \%$ performed it on a monthly basis. Only $25 \%$ of participants were categorized as possessing a satisfactory knowledge of breast cancer.

Awareness and understanding of breast cancer is particularly low within the general population of Africa, outside of urbanized areas. In one study, for example, supernatural etiology was the most commonly cited reason by western African women for the cause of breast cancer. ${ }^{55}$ In another study, $60 \%$ of the East Africans surveyed reported that they would consult health personnel when sick, with the remainder stating a preference to consult traditional healers. ${ }^{56}$ In South Africa, approximately $25 \%$ of urban women and more than $33 \%$ of rural women reported that they would initially seek traditional healers for advice regarding breast lumps. ${ }^{57}$

Competing health care threats. Developing countries clearly face a myriad of health-related problems and medical needs, including widespread malnutrition, infant mortality, inadequate childhood vaccination programs, and growth of human immunodeficiency virus and/or acquired immunodeficiency syndrome (HIV/ AIDS) epidemic. Many of these problems result in a shortened lifespan among women, and the age of greatest breast cancer risk is never reached. Indeed, Amir et al. ${ }^{58}$ reported a decrease in breast cancer incidence documented by the Tanzanian Cancer Reg- istry during the 1968-1996 AIDS epidemic. Guth ${ }^{59}$ attempted to correlate estimates of the growing burden of breast cancer in sub-Saharan Africa with the expanding HIV problem. It is estimated that by the end of the year 2000, more than 36 million people, mostly in sub-Saharan Africa, were infected with HIV. Retroviral therapies that were developed in the western world have increased the longevity of HIV-positive individuals dramatically, and infected but properly treated women are more likely to reach age ranges where breast cancer risk peaks. Analysis by Guth of available data suggested that HIV infection does not appear to be permissive of breast cancer (because very few cases have been reported of HIV coexisting with breast cancer), and that whereas hormonal therapy for breast cancer is well tolerated by HIV-positive patients, chemotherapy is associated with excessive toxicity.

\section{Breast Cancer in Africans and African Americans}

The epidemiology of breast cancer among women of sub-Saharan Africa is similar to that of African-American women as both groups have relatively low incidence rates, paradoxically higher mortality rates, increased prevalence of early-onset disease, and advanced stage tumors. These patterns, as well as comparisons with other ethnic subsets of the USA population, are shown in Figure 3 and Table 2. These observations may be at least partially explained by statistical similarities in reproductive patterns and socioeconomic resources. Utilization rates for mammographic screening, with an associated potential for lead-time bias and a consequential effect on incidence rates, ${ }^{60,61}$ may also produce statistical variations in breast cancer epidemiology among African, AfricanAmerican, and White-American women. The collective influences of parity, socioeconomic status, screening rates, and hereditary factors on ethnicityrelated breast cancer risk deserves further study.

African-American women tend to initiate childbearing at relatively younger ages compared with White-American women, and this reproductive lifestyle has been implicated as a possible explanation for the younger age distribution reported for African American breast cancer patients. Although lifetime risk of breast cancer is lower in women that have multiple pregnancies (especially if the first full term pregnancy occurs at a young age), there is a brief increase in breast cancer risk during the $6-12$ months postpartum period. ${ }^{62}$ It is possible that the early-onset pregnancies yield a younger breast cancer age distribution. This "dual effect" of parity has been supported by findings from of the Black Women's Health Study ${ }^{63}$ but refuted by epidemiologic analysis by the Women's 
FIGURE 3. Breast cancer incidence and mortality among population subsets within the USA 1 and compared with Africa. $^{11}$

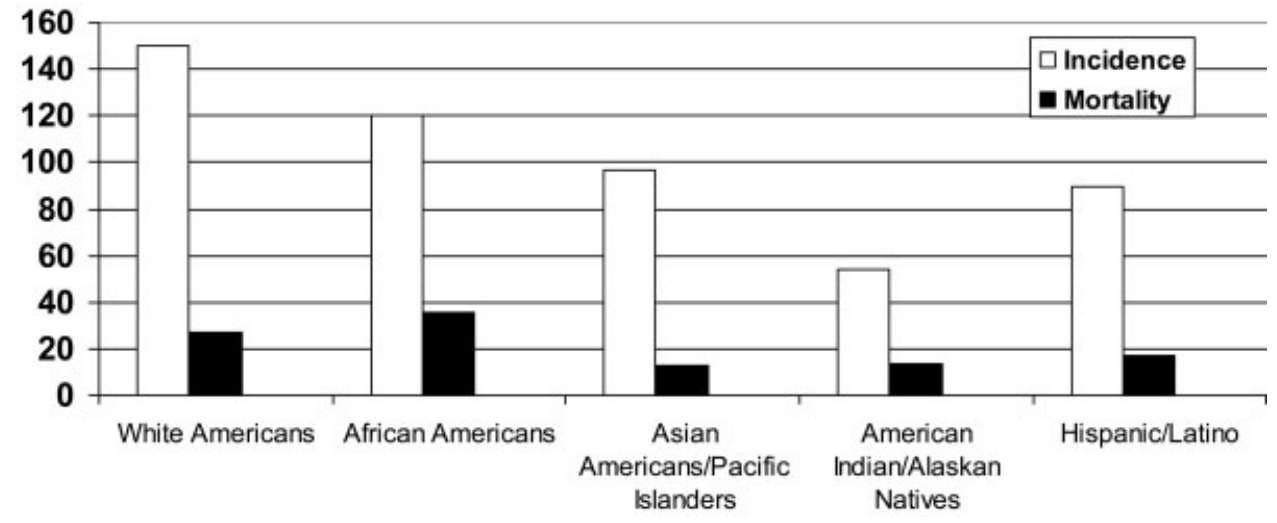

TABLE 1

Breast Cancer in African Americans and Women from Sub-Saharan Africa: Features That Have Been Documented, and Features That Require Further Research

\begin{tabular}{|c|c|c|}
\hline Feature & African Americans & Sub-Saharan Africans \\
\hline Incidence rates & $120 / 100,000^{1}$ & $10-40 / 100,000^{11}$ \\
\hline Mortality rates & $38 / 100,000^{1}$ & $5-20 / 100,000^{11}$ \\
\hline Age distribution & $\begin{array}{l}\text { Increasing incidence with age; among women aged }<45 \\
\text { yrs, incidence higher for African Americans compared } \\
\text { with White Americans }{ }^{1}\end{array}$ & $\begin{array}{l}\text { Median age at diagnosis, } 40-49 \text { yrs; incidence } \\
\text { among elderly uncertain because of shorter } \\
\text { life expectancy in African populations }{ }^{16-20,23}\end{array}$ \\
\hline Stage distribution at diagnosis & $\begin{array}{l}\text { More advanced compared with White Americans; } 10- \\
20 \% \text { detected as Stage III disease }{ }^{1}\end{array}$ & $\begin{array}{l}\text { Majority of cases detected as Stage III } \\
\text { disease. }{ }^{16,18,19,38}\end{array}$ \\
\hline $\begin{array}{l}\text { Tumor grade and indices of } \\
\text { proliferation }\end{array}$ & Increased prevalence of high-grade disease $(37-54 \%)^{2,3,5}$ & Increased prevalence of high-grade disease ${ }^{41-43}$ \\
\hline Estrogen receptor expression & $\begin{array}{l}\text { Increased prevalence of estrogen receptor-negative } \\
\text { tumors compared with White Americans }\end{array}$ & $\begin{array}{l}\text { Limited availability of testing for hormone } \\
\text { receptor assays }\end{array}$ \\
\hline
\end{tabular}

Contraceptive and Reproductive Experiences casecontrol study. ${ }^{64}$ Similarly, other investigators have suggested that differences in reproductive patterns may explain variations in primary tumor biology and tumor aggressiveness. ${ }^{65,66}$ These issues have not been evaluated in the African breast cancer population and remain incompletely understood in African-American women.

African Americans have higher poverty rates and diminished access to health care compared with White Americans. However, the socioeconomic disadvantages that are more prevalent among African Americans compared with White Americans do not consistently account for disparities in breast cancer outcomes. $^{67}$ The impact of socioeconomics is explored in further detail by Newman et al. ${ }^{67}$

The common ancestry shared by sub-Saharan Africans and African Americans, therefore, merits evaluation as a possible hereditary contributor to these parallels in breast cancer burden. In the 17th and 18th centuries, millions of Africans were removed from their countries and shipped to North America as slaves. ${ }^{68}$ It is estimated that $66 \%$ of the Africans brought to the USA were from western Africa and fewer from central Africa. Slave ports existed in present-day Nigeria, Ghana, Cameroon, Togo, Benin, Burkina Faso, Ivory Coast, Gambia, Guinea, Senegal, Guinea Bissau, and as far south as Angola.

This shared ancestry further raises the possibility that some inherited genotypes related to estrogen metabolism and/or breast cancer risk may exist that increase the risk of early-onset, locally advanced, breast tumors. Also, germline mutations in breast cancerpredisposing genes place affected individuals at increased risk for early onset, high-grade, hormone receptor-negative disease, and these are features that characterize African-American breast cancer patients. Unfortunately, genetic counseling programs have tended to be underused by African Americans because of high cost, limited access, and, probably, cultural beliefs. As reviewed in detail by Olopade et al., ${ }^{69}$ several distinct mutations in the BRCA1 and BRCA2 genes have been identified among African-American families ${ }^{70-72}$ but there is presently insufficient test data available to draw firm conclusions concerning the prevalence of founder mutations. Also, conducting hereditary predisposition studies of African ancestry is complicated by challenges in collecting accurate in- 
formation on ethnic backgrounds of many American families.

A mutation in BRCA1, 943ins10, was identified in families of western African ancestry from Florida, the District of Columbia, South Carolina, the Bahamas, and the Ivory Coast, ${ }^{70,71}$ and this mutation appears to be a strong candidate for a founder mutation. It is also possible that founder mutations specific to families of African ancestry may exist in breast cancer susceptibility genes that have not yet been identified. BRCA gene mutations are estimated to be responsible for approximately $50 \%$ of breast cancers that occur in high-risk families.

\section{CONCLUSION}

Breast cancer burden is likely to grow substantially in Africa. As a westernized lifestyle (with its associated reproductive patterns and dietary patterns) is adopted, breast cancer incidence rates will rise. Unless medical care and screening practices are dramatically improved, breast cancer mortality rates can be expected to remain disproportionately high. The parallels between African-American and sub-Saharan-African breast cancer patients suggests the possible effects of hereditary factors, and these influences may cause the younger age distribution that is seen among these patient populations to persist. Substantial differences in reproductive patterns and lifestyle between women of African descent compared with European descent play a role in defining these variations in breast cancer risk as well. Larger prospective studies with accurate molecular biology, data collection, and statistical analyses are required, as the studies reported to date from African health care facilities frequently lack hormone receptor status and detailed risk factor information. Investment of funds from more affluent western health care communities into oncology programs of Africa to support data collection and tumor marker analyses would be beneficial to African populations, and it would also contribute to our understanding of breast cancer risk related to African ancestry. As research into interactions among tumor biology, genetics, and socioeconomics and/or lifestyle factors continues, medical professionals and researchers will be in a stronger position to address and to eradicate the disproportionate breast cancer burden that currently affects African-American women.

\section{REFERENCES}

1. Ries L, Eisner M, Kosary C, Hankey B, Miller B, Clegg L, et al. SEER cancer statistics review, 1975-2001. Vol. 2004. URL: http://seer.cancer.gov/csr/1975_2001/. [Accession date, 2004].

2. Li CI, Malone KE, Daling JR. Differences in breast cancer hormone receptor status and histology by race and ethnicity among women 50 years of age and older. Cancer Epidemiol Biomarkers Prev. 2002;11:601-607.

3. Li CI, Malone KE, Daling JR. Differences in breast cancer stage, treatment, and survival by race and ethnicity. Arch Intern Med. 2003;163:49-56.

4. Newman LA, Bunner S, Carolin K, Bouwman D, Kosir MA, White M, et al. Ethnicity related differences in the survival of young breast carcinoma patients. Cancer 2002;95:21-27.

5. Shavers VL, Harlan LC, Stevens JL. Racial/ethnic variation in clinical presentation, treatment, and survival among breast cancer patients under age 35. Cancer. 2003;97:134-147.

6. Jones B, Kasl S, Howe C, Lachman M, Dubrow R, Curnen M, et al. African American/White differences in breast carcinoma: p53 alterations and other tumor characteristics. Cancer. 2004;101:1293-1301.

7. Porter PL, Lund MJ, Lin MG, Yuan X, Liff JM, Flagg EW, et al. Racial differences in the expression of cell cycle-regulatory proteins in breast carcinoma. Cancer. 2004;100:2533-2542.

8. Elledge RM, Clark GM, Chamness GC, Osborne CK. Tumor biologic factors and breast cancer prognosis among white, Hispanic, and black women in the United States. J Natl Cancer Inst. 1994;86:705-712.

9. Salas A, Richards M, Lareu MV, Scozzari R, Coppa A, Torroni A, et al. The African diaspora: mitochondrial DNA and the Atlantic slave trade. Am J Hum Genet. 2004;74:454-465.

10. Sandelin K, Apffelstaedt JP, Abdullah H, Murray EM, Ajuluchuku EU. Breast surgery international-breast cancer in developing countries. Scand J Surg. 2002;91:222-226.

11. International Agency for Research on Cancer. Globocan 2000: cancer incidence, mortality and prevalence worldwide. Lyon, France: IARC Press. 2001.

12. Hoffman M, de Pinho H, Cooper D, Sayed R, Dent DM, Gudgeon A, et al. Breast cancer incidence and determinants of cancer stage in the Western Cape. S Afr Med J. 2000;90: $1212-1216$.

13. Vorobiof DA, Sitas F, Vorobiof G. Breast cancer incidence in South Africa. J Clin Oncol. 2001;19(18 Suppl):125S-127S.

14. Uganda Breast Cancer Working Group. Breast cancer guidelines for Uganda. Afr Health Sci. 2003;3:47-50.

15. Parkin DM. Cancer in developing countries. Cancer Surv. 1994;19-20:519-561.

16. Amir H, Kitinya JN, Parkin DM. A comparative study of carcinoma of the breast in an African population. East Afr Med J. 1994;71:215-218.

17. Anyanwu SN. Breast cancer in eastern Nigeria: a ten year review. West Afr J Med. 2000;19:120-125.

18. Hassan I, Onukak EE, Mabogunje OA. Breast cancer in Zaria, Nigeria. J R Coll Surg Edinb. 1992;37:159-161.

19. Muguti GI. Experience with breast cancer in Zimbabwe. $J R$ Coll Surg Edinb. 1993;38:75-78.

20. Amir H, Makwaya CK, Aziz MR, Jessani S. Breast cancer and risk factors in an African population: a case referent study. East Afr Med J. 1998;75:268-270.

21. Adebamowo CA, Ogundiran TO, Adenipekun AA, Oyesegun RA, Campbell OB, Akang EU, et al. Obesity and height in urban Nigerian women with breast cancer. Ann Epidemiol. 2003;13:455-461.

22. Yawitch TM, van Rensburg EJ, Mertz M, Falkson CI. Absence of commonly recurring BRCA1 mutations in black South African women with breast cancer. S Afr Med J. 2000;90:788.

23. Ihekwaba FN. Breast cancer in Nigerian women. Br J Surg. 1992;79:771-775. 
24. Muthuphei MN. Carcinoma of the breast at Ga-Rankuwa Hospital histopathology laboratory (South Africa). Cent Afr J Med. 1994;40:254-257.

25. Adebamowo CA, Ajayi OO. Breast cancer in Nigeria. West Afr J Med. 2000;19:179-191.

26. World Health Organization. Life tables for 191 countries: world mortality in 2000. URL: http://www3.who.int/whosis/ life/life_tables/life_tables.cfm?path=whosis,burden_statistics, life,life_tables\&language $=$ English. [Accession date, 2000].

27. Jones SB. Cancer in the developing world: a call to action. BMJ. 1999;319:505-508.

28. World Health Organization. Mortality by sex, cause, and WHO region, estimates for 1998. In: The World Health Organization Report 1999. Making a difference. Geneva, Switzerland: World Health Organization. 1999.

29. Rosenberg L, Kelly JP, Shapiro S, Hoffman M, Cooper D. Risk factors for breast cancer in South African women. S Afr Med J. 2002;92:447-448.

30. Parkin DM, Vizcaino AP, Skinner ME, Ndhlovu A. Cancer patterns and risk factors in the African population of southwestern Zimbabwe, 1963-1977. Cancer Epidemiol Biomarkers Prev. 1994;3:537-547.

31. Strassmann BI. Menstrual cycling and breast cancer: an evolutionary perspective. J Womens Health. 1999;8:193-202.

32. Coogan PF, Rosenberg L, Shapiro S, Hoffman M. Lactation and breast carcinoma risk in a South African population. Cancer. 1999;86:982-989.

33. Djuric Z, Depper JB, Uhley V, Smith D, Lababidi S, Martino $S$, et al. Oxidative DNA damage levels in blood from women at high risk for breast cancer are associated with dietary intakes of meats, vegetables, and fruits. J Am Diet Assoc. 1998;98:524-528.

34. Boyd NF, Stone J, Vogt KN, Connelly BS, Martin LJ, Minkin S. Dietary fat and breast cancer risk revisited: a meta-analysis of the published literature. Br J Cancer. 2003;89:16721685 .

35. Izevbigie EB. Discovery of water-soluble anticancer agents (edotides) from a vegetable found in Benin City, Nigeria. Exp Biol Med (Maywood). 2003;228:293-298.

36. Adebamowo CA, Ogundiran TO, Adenipekun AA, Oyesegun RA, Campbell OB, Akang EE, et al. Waist-hip ratio and breast cancer risk in urbanized Nigerian women. Breast Cancer Res. 2003;5:R18-24.

37. Ziegler RG, Hoover RN, Pike MC, Hildesheim A, Nomura AM, West DW, et al. Migration patterns and breast cancer risk in Asian-American women. J Natl Cancer Inst. 1993;85: 1819-1827.

38. Amir H, Azizi MR, Makwaya CK, Jessani S. TNM classification and breast cancer in an African population: a descriptive study. Cent Afr J Med. 1997;43:357-359.

39. Hassan I, Muhammed I, Attah MM, Mabogunje O. Breast cancer during pregnancy and lactation in Zaria, Nigeria. East Afr Med J. 1995;72:280-282.

40. Dansey RD, Hessel PA, Browde S, Lange M, Derman D, Nissenbaum $M$, et al. Lack of a significant independent effect of race on survival in breast cancer. Cancer. 1988;61: $1908-1912$.

41. Ikpatt OF, Kuopio T, Collan Y. Proliferation in African breast cancer: biology and prognostication in nigerian breast cancer material. Mod Pathol. 2002;15:783-789.

42. Bjerregaard B, Kung'u A. Breast cancer in Kenya: a histopathologic and epidemiologic study. East Afr Med J. 1992; 69:22-26.

43. Ikpatt F, Kuopio T, Erekul A, Collan Y. Apoptosis in breast cancer: Nigerian vs. Finnish material. Anal Quant Cytol Histol. 2002;24:73-80.

44. Ikpatt OF, Kuopio T, Ndoma-Egba R, Collan Y. Breast cancer in Nigeria and Finland: epidemiological, clinical and histological comparison. Anticancer Res. 2002;22:3005-3012.

45. Gao Q, Adebamowo CA, Fackenthal J, Das S, Sveen L, Falusi AG, et al. Protein truncating BRCA1 and BRCA2 mutations in African women with pre-menopausal breast cancer. Hum Genet. 2000;107:192-194.

46. Szabo CI, King MC. Population genetics of BRCA1 and BRCA2. Am J Hum Genet. 1997;60:1013-1020.

47. Yamauchi H, Stearns V, Hayes DF. When is a tumor marker ready for prime time? A case study of c-erbB-2 as a predictive factor in breast cancer. J Clin Oncol. 2001;19:2334-2356.

48. Xie D, Shu X. Population-based, case-control study of HER2 genetic polymorphism and breast cancer risk. J Natl Cancer Inst. 2000;92:412-417.

49. Ameyaw M, Thornton N, McLeod H. Re: Population-based, case-control study of HER2 genetic polymorphism and breast cancer risk. J Natl Cancer Inst. 2000;92:1947.

50. World Health Organization. World Health Organization per capita health care expenditures, vol. 2004. Geneva, Switzerland: World Health Organization. URL: http://www. who.int/en, [Accessed, 2004].

51. Othieno-Abinya NA, Nyabola LO, Abwao HO, Ndege P. Postsurgical management of patients with breast cancer at Kenyatta National Hospital. East Afr Med J. 2002;79:156-162.

52. Harder H. Role of ovarian ablation for premenopausal patients in adjuvant systemic therapy of breast cancer. Trop Doct. 1996;26:85.

53. Odusanya OO, Tayo OO. Breast cancer knowledge, attitudes and practice among nurses in Lagos, Nigeria. Acta Oncol. 2001;40:844-848.

54. Odusanya OO. Breast cancer: knowledge, attitudes, and practices of female schoolteachers in Lagos, Nigeria. Breast J. 2001;7:171-175.

55. Ohaeri JU, Campbell OB, Ilesanmi A, Ohaeri BM. The opinion of caregivers of some women with breast and cervical cancer on aspects of the disease. West Afr J Med. 1999;18:6-12.

56. Nzarubara RG. Control of breast cancer using health education. East Afr Med J. 1999;76:661-663.

57. Pillay A. Rural and urban South Africa women's awareness of cancers of the breast and cervix. Ethn Health. 2002;7:103114.

58. Amir H, Kaaya EE, Kwesigabo G, Kiitinya JN. Breast cancer before and during the AIDS epidemic in women and men: a study of Tanzanian Cancer Registry Data 1968 to 1996. J Natl Med Assoc. 2000;92:301-305.

59. Guth AA. Breast cancer and human immunodeficiency virus infection: issues for the 21st century. J Womens Health (Larchmt). 2003;12:227-232.

60. Black WC, Welch HG. Advances in diagnostic imaging and overestimations of disease prevalence and the benefits of therapy. N Engl J Med. 1993;328:1237-1243.

61. Zahl PH, Strand BH, Maehlen J. Incidence of breast cancer in Norway and Sweden during introduction of nationwide screening: prospective cohort study. BMJ. 2004;328: 921-924.

62. Pathak DR, Osuch JR, He J. Breast carcinoma etiology: current knowledge and new insights into the effects of reproductive and hormonal risk factors in black and white populations. Cancer. 2000;88(5 Suppl):1230-1238. 
63. Palmer JR, Wise LA, Horton NJ, Adams-Campbell LL, Rosenberg L. Dual effect of parity on breast cancer risk in AfricanAmerican women. J Natl Cancer Inst. 2003;95:478-483.

64. Ursin G, Bernstein L, Wang Y, Lord SJ, Deapen D, Liff JM, et al. Reproductive factors and risk of breast carcinoma in a study of white and African-American women. Cancer. 2004; 101:353-362.

65. Althuis MD, Fergenbaum JH, Garcia-Closas M, Brinton LA, Madigan MP, Sherman ME. Etiology of hormone receptor-defined breast cancer: a systematic review of the literature. Cancer Epidemiol Biomarkers Prev. 2004;13: $1558-1568$.

66. Wohlfahrt J, Andersen PK, Mouridsen HT, Adami HO, Melbye M. Reproductive history and stage of breast cancer. Am J Epidemiol. 1999;150:1325-1330.

67. Newman LA, Mason J, Cote D, Vin Y, Carolin K, Bouwman D, et al. African-American ethnicity, socioeconomic status, and breast cancer survival: a meta-analysis of 14 studies involving over 10,000 African-American and 40,000 White
American patients with carcinoma of the breast. Cancer. 2002;94:2844-2854.

68. Ijaduola TG, Smith EB. Pattern of breast cancer among white-American, African-American, and nonimmigrant west-African women. J Natl Med Assoc. 1998;90:547-551.

69. Olopade OI FJ, Dunston G, Tainsky MA, Collins F, WhitfieldBroome C. Breast cancer genetics in African Americans. Cancer. 2002;97(1Suppl):236-245.

70. Mefford HC, Baumbach L, Panguluri RC, Whitfield-Broome C, Szabo C, Smith S, et al. Evidence for a BRCAl founder mutation in families of West African ancestry. Am J Hum Genet. 1999;65:575-578.

71. Panguluri RC BL, Modali R, Utley K, Adams-Campbell L, Day AA, Whitfield-Broome C, Dunston GM. BRCA mutations in African Americans. Hum Genet. 1999;105:28-31.

72. Gao Q, Tomlinson G, Das S, Cummings S, Sveen L, Fackenthal J, et al. Prevalence of BRCA1 and BRCA2 mutations among clinic-based African American families with breast cancer. Hum Genet. 2000;107:186-191. 